\title{
TREATMENT OF AORTIC INSUFFICIENCY BY THE HUFNAGEL VALVE WITH FOUR ILLUSTRATIVE CASES
}

\author{
By A. W. FawCETT, F.R.C.S. \\ Thoracic Surgeon, The Royal Infirmary, Sheffield \\ and B. S. Dhillon, F.R.C.S. \\ Surgical First Assistant and Registrar to the Thoracic Surgical Unit
}

In 1944 Dr. Charles Hufnagel began experimental work on animals in attempts to evolve a suitable valve for the treatment of aortic insufficiency.

He has, over a number of years since, used a variety of material, including homologous valves, pericardium, veins, etc., but none was satisfactory, as they all showed signs of wear and tear in the long run. This led to the design of a plastic valve.

The valves are made of methyl methacrylate, with at first a polythene ball, but recently the ball has been changed to one of the same material as the rest of the valve. The valve is held in the aorta by two nylon rings. They are toothed and the teeth have to be longer than the thickness of the aorta, otherwise the aorta will slough. In this way the blood supply to the very edge of the aorta is preserved. The valves are made in four sizes, from $\frac{3}{4}$ in. to $1 \frac{1}{8}$ in. The nylon rings are grooved round the edge to hold a silk ligature, which prior to operation must be tied in several places or the silk will slip out of the groove. Alongside the split are two holes to fasten the ends together with stainless steel wire after tying the silk. The rings should be placed on the aorta before it is divided.

\section{Operative Procedure}

The patient is placed in the right lateral position and the left side of the thorax is entered through the bed of the resected fifth or sixth rib. The aorta is mobilized over a length of about 4 in. and four intercostal vessels, and possibly an oesophageal artery, are cleared and divided. The nylon rings are then passed round the aorta whilst it is intact. The valve should be sterilized in zephirin or some similar antiseptic for 18 hours and then triple rinsed in saline solution before use. The aorta is clamped at the top and bottom ends of the freed portion and divided in the middle, or a segment is removed as recommended by Dr. Huf-

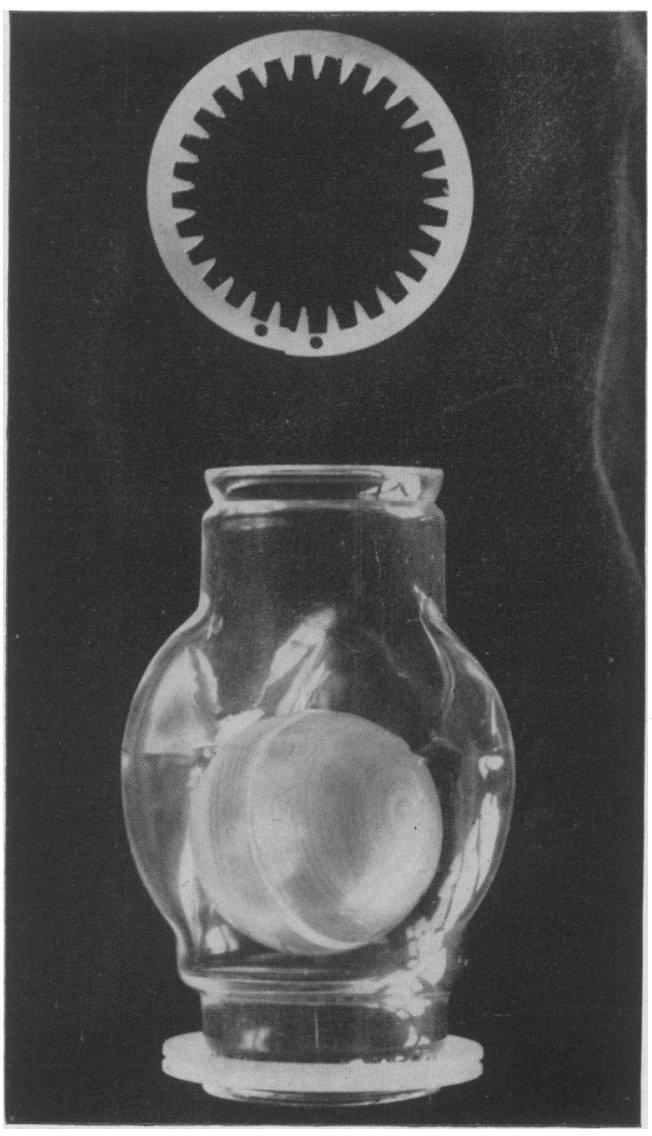

nagel. It is essential not to have any overlapping $\widetilde{N}$ of the aorta against the nylon ring or it will slough $N$ and burst. Actually, the aorta seems to retract so N much that we have been afraid to resect any and we did not note any overlapping tendency. The valve is introduced into the lower end first and the nylon ring pulled over it and tied, using Allis's forceps to hold the edge of the aorta. The teeth are 
apt to catch in the adventitious tissue and make the manoeuvre difficult. The nylon ring is finally fixed by the wire, which is placed through the two eyes and twisted until firm. The upper end is then treated in the same way. Finding that Allis's forceps got in the way, we used silk ligatures at equidistant points through the edges of the aorta. They do not tear out even with a very strong pull and we feel that they are easier to manage. Just before fitting the upper end heparinized saline is introduced into the lumen of the valve and, if possible, all the air is eliminated. Some remains trapped and can be removed by introducing a fine, bent, long hypodermic needle, introduced through the aorta into the chamber.

Dr. Hufnagel now wraps the two ends of the aorta with $I \frac{1}{2}$-in. wide orlon, which helps to eliminate the aorta bulging over the nylon ring and so prevents sloughing. Technically, the operation is difficult when the heart is large, and if the aorta is atheromatous it may crack when the clamps are applied and such cases should be avoided. The aorta should not be clamped for more than 10 minutes if it is possible.

Dr. Hufnagel reported 50 terminal cases of disease operated upon with a mortality of 20 per cent. Many of these cases were such bad risks that when anaesthetized they became so desperate that attempts to do any operation had to be postponed until a later date. He has never failed to insert a valve. The patients' ages have ranged from 17 to 54 years.

Fifteen per cent. of the cases developed embolic phenomena, but for no obvious reason during the past year none have done so. In a group of 80 patients, 12 were not able to be operated upon at the first attempt. Dr. Hufnagel tells us (personal communication) that a number of patients have survived for over three years and are still well, and able to lead a normal life.

His latest results are: 20 per cent. of the patients die in hospital, 20 per cent. die within two years and 60 per cent. are living a relatively normal life.

\section{Causes of Death}

Pre- and post-operative clamping and unclamping of the aorta may apparently lead to sudden death. Haemorrhage, embolism, congestive heart failure, subacute bacterial endocarditis and postoperative anaemia are other causes of death.

\section{Changes in the Circulation After Introduction of the Valve}

The heart shrinks in size. This may be noticed during a successful valve insertion whilst the chest is still open. It occurs, in any case, later in all surviving cases. Any increased cardiac work necessitates increased myocardial oxygen require- ments. After the insertion of the valve 75 per cent. of the blood flow from the heart continues in a forward direction, but as this probably results in a diminished coronary flow the chances of immediate benefit may be rather a gamble. The blood supply to the subclavian and carotid vessels and to the coronary vessels remains unchanged and is regurgitant. The femoral vessels exhibit a near normal pressure, both systolic and diastolic. The total output from the heart is much decreased and pulmonary congestion is diminished. The total blood volume is unchanged.

\section{Post-operative Complications}

I. Haemorrhage.

2. Collapse of the lung.

3. Anaemia due to haemolysis.

4. Subacute bacterial endocarditis.

5. Reactivation of the rheumatic process.

6. Massive pleural effusion.

7. Sudden death after many months. Probably coronary thrombosis.

8. Multiple infarcts of the mesentery, kidneys, etc.

9. Bouts of ventricular tachycardia.

Although the method used by Hufnagel is probably not the final answer, it does seem at the moment to offer sufferers from aortic incompetence some hope. Dr. Hufnagel has a number of patients who have survived for over three years and who are leading relatively normal lives, so there is hope that they may continue to do so and that there may not be even later complications.

The following cases suffering from Aortic Incompetence have been operated upon in the Royal Infirmary, Sheffield

\section{Case I}

F.M.S., a woman aged 20 years, was admitted to the Royal Infirmary on $27 \cdot 3 \cdot 55$. She had rheumatic fever at the age of six and aortic incompetence was diagnosed in I948. She had had dyspnoea for the past I 3 years. She had a very restricted life for the past six years and could walk only about ro yards before becoming very breathless. She also experienced attacks of substernal pain, which were always accompanied by palpitation for the past two years.

Examination. Radial pulse was ' water hammer' in quality, regular, and rate was roo per minute. There was forceful pulsation of the vessels in the neck and abdomen and it imparted a to and fro motion to the entire head and trunk with each heart beat. The blood pressure was $182 / 20 \mathrm{~mm}$. of $\mathrm{Hg}$. in the upper limbs and $260 / \mathrm{mm}$. of $\mathrm{Hg}$. in the lower limbs. A 'pistol shot' sound in the femoral artery was heard on auscultation and Duroziez's sign was present. The apex beat was in 
the left sixth intercostal space in the anterior axillary line and was heaving in quality. There was a diastolic murmur, soft and high-pitched, starting immediately after the second heart sound, best heard along the left sternal border in the second, third and fourth intercostal spaces. The murmur occupied the whole of diastole and it was conducted to the apex. Radiologically, the heart showed enlargement of the left ventricle. The electrocardiogram showed abnormal left ventricular preponderance.

Operation (5.4.55). The left chest was entered through the bed of the resected fifth rib. About $8 \mathrm{~cm}$. of aorta was mobilized from the origin of the left subclavian artery after division of the four intercostal vessels. The aorta was then clamped and divided. No aortic segment was excised, as there was a $I \frac{1}{2}$-in. gap after section. Using Allis's forceps, the valve was, with difficulty, placed in the lower end of the aorta, about 3 in. above the diaphragm. It was found that the forceps were a nuisance and wasted time and it was felt that sutures might be better. As a result of loss of time, some 40 minutes elapsed before the valve was finally in place and the clamps released. The valve was working satisfactorily, but in a very short time, possibly with the sudden alteration in pressures, ventricular fibrillation started and, in spite of efforts to keep the heart going, it soon ceased to function and the patient died.

Necropsy showed very enlarged heart due to the marked hypertrophy of the left ventricle. The aortic valves were sclerosed and shrunken due to old rheumatic endocarditis. The mitral valve, tricuspid valve and pulmonary valves were normal.

\section{Case 2}

A.B., a married woman aged 20 , was admitted to the Royal Infirmary on $14 \cdot 4 \cdot 55$. She had rheumatic fever at the age of eight and soon after this it was noticed that she was breathless on exertion. For the past six years she had severe limitation of her activities from dyspnoea and she developed attacks of paroxysmal dyspnoea for a few weeks before admission. She also noticed brief, sharp stabbing pain in the precordium unrelated to exertion and attacks of substernal pain radiating to the back and the left arm. The latter attacks of pain were due to paroxysmal angina pectoris and during these attacks, which lasted for a variable time (five to 15 minutes), she had raised blood pressure, palpitation and flushing.

Examination. Radial pulse was 80 per minute, irregular and ' water hammer' quality. She had hyperactive pulsation of the carotid arteries and the body shook with each heart beat. She had ' pistol shot' sound in the femorals and Duroziez's sign was present. Her blood pressure was $15 \%$

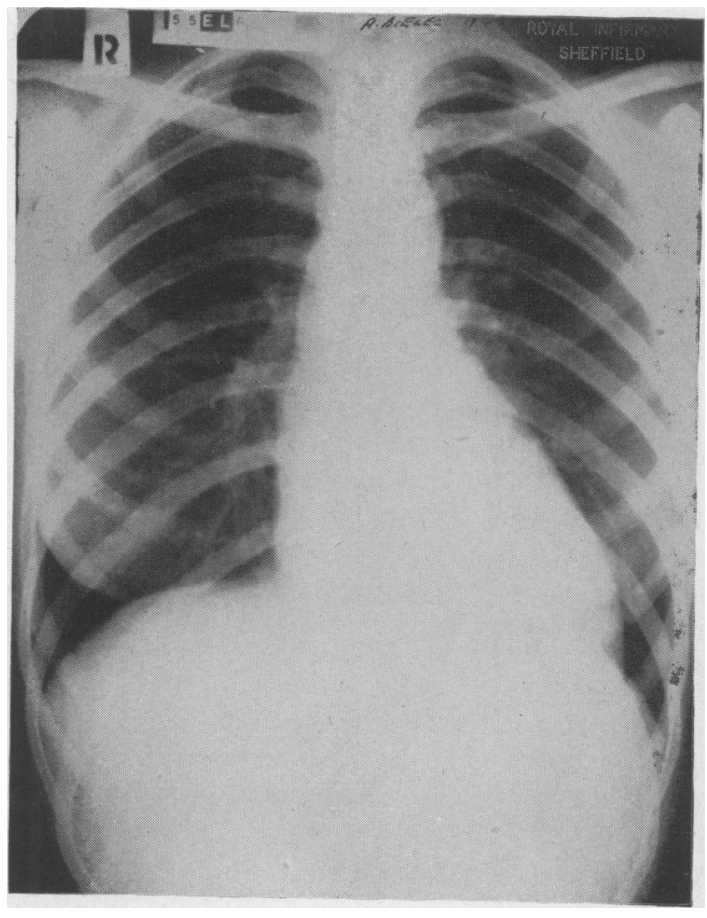

Case 2. Before operation.

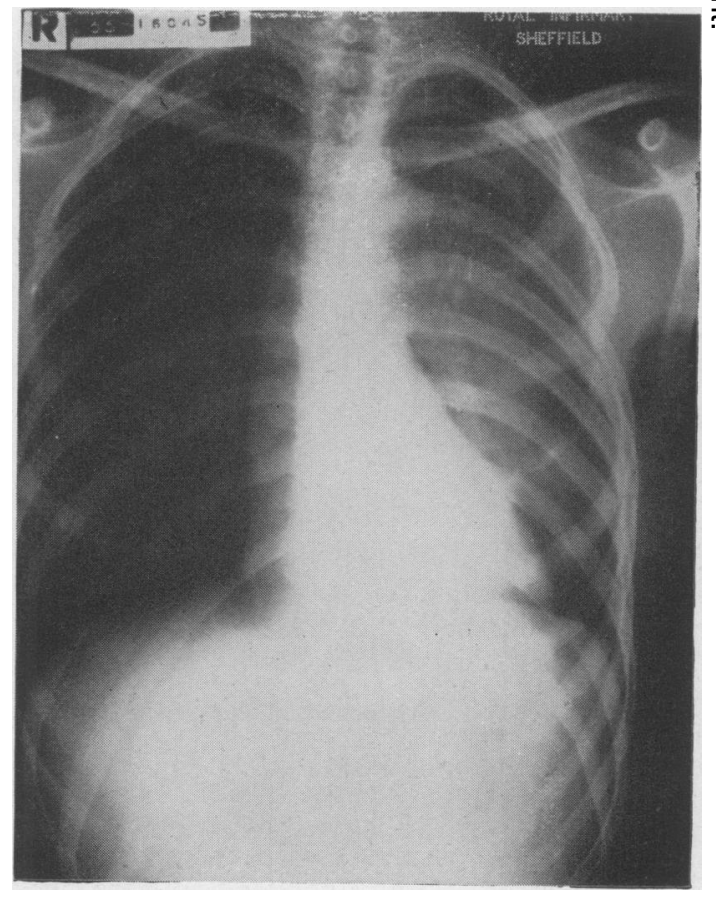

Case 2. After operation. 
in the upper limbs and $300 / 0$ in the lower limbs. The apex beat was in the left sixth intercostal space in the mid-axillary line and was heaving in quality. There was a basal systolic and diastolic murmur. The diastolic murmur was soft and high-pitched, starting with the second sound and filling the whole of the diastole. It was best heard in the left parasternal area in the third and fourth intercostal spaces. The basal systolic murmur was harsh. Electrocardiogram showed abnormal left ventricular preponderance and ventricular extrasystoles. Fluoroscopy showed enlargement of the left ventricle.

Operation (21.4.55). The left thorax was entered through the bed of the resected fifth rib. About $8 \mathrm{~cm}$. of descending aorta was mobilized from the origin of the left subclavian artery after division of four intercostal and one oesophageal vessels. The aorta was clamped and the nylon rings were placed over the intact aorta. The aorta was divided in the middle and four stay sutures were inserted at equidistant points in either end of the divided aorta. The valve was then placed in position and fixed. This method seemed to be easier than using Allis's forceps and the valve was in place in 25 minutes.

Post-operative Progress. She had to be maintained on assisted breathing for four hours (intratracheal tube intubation and positive pressure), due to temporary paralysis of her intercostal muscles. She was given 2,250 c.c. of intravenous blood transfusion during the operation and 2,700 c.c. of whole blood was given by the intravenous route over the following 24 hours. The blood pressure was stabilized at $134 / 0$ in the upper limbs before discontinuing the drip. It was estimated that she lost about 4,000 c.c. during the operation and in the following 24 hours. Her ventricular extrasystoles were controlled by adequate doses of procaine-amide, which was then discontinued. Her haemoglobin varied between $13.6 \mathrm{~g}$./100 $\mathrm{ml}$. and $12.4 \mathrm{~g}$./100 $\mathrm{ml}$. during the remainder of her stay in hospital and there did not appear to be any abnormal destruction of the red blood corpuscles.

She was discharged home on 27.5 .55 . She was seen frequently at the out-patient department and it was found that there was marked amelioration of her symptoms. She was no longer dyspnoeic and did her household duties. The precordial pain was completely relieved. Her blood pressure in the upper limb was $160 / 0$ and the blood pressure in the lower limbs was 135/70. Radiologically, the heart was half its original size. The clicking noise of the valve could be heard at a distance of several feet, but it did not inconvenience her in any way.

She remained well and happy until September, when she developed pain in the left shoulder, which gradually became worse, and for this she was eventually readmitted on 5.9 .55 . The pain was severe and continuous and was situated between the vertebral column and the edge of the scapula. Fears were expressed that she was either developing pressure on the vertebral column with erosion, an aneurysm or leakage. The blood pressure in the arm was $160 / 0$. Blood cultures were negative, radiography of the chest showed nothing abnormal except that the valve appeared to have moved a little laterally.

12.9.55. The pain, which had become much worse, was still in the same place, sometimes radiating down the vertebral column and arms.

15.9.55. Pulsation was noted for the first time between the vertebral border and the scapula and an aneurysm was diagnosed. There was no change in the valve sound, which was functioning as well as ever. The blood pressure in the arm was $130 / 0$ and both radial pulses were equal. For the first time she had a haemoptysis.

17.9.55. She died suddenly.

Post-mortem Examination. The old wound was reopened and a large amount of blood and clot was found in the posterior and upper part of the left chest. The upper lobe of the lung was collapsed and lying in front of this. On removal of the clot it was seen that the outer edge of the proximal aorta had parted from the valve, though the inner edge was still held by the nylon ring. A sudden flow of blood had occurred. Probably there had been a small leak for some days before death, though there was little to confirm this.

\section{Case 3}

G.A., a married woman aged 38 years, was admitted to the Royal Infirmary on 18.10 .55 . She had rheumatic fever at the age of five and in I948, following dental extraction, she developed subacute bacterial endocarditis. She had marked limitation of activities for the past Io years from dyspnoea. She also developed attacks of paroxysmal angina pectoris, radiating to the neck and both the arms. These attacks of pain had gradually become worse over the past three years and more recently these attacks of pain had occurred five or more times a day. She had been taking about 20 tablets of nitroglycerine for the relief of this pain.

Examination. The radial pulse was 80 , regular and was of ' water hammer' quality. There was marked pulsation of the carotid arteries and the body shook with each heart beat. 'Pistol shot' sounds very audible over the femoral artery and Duroziez's sign was present. The blood pressure was $210 \%$ in the upper limbs and $260 / 0$ in the lower limbs. The apex beat was in the sixth intercostal space in the mid-axillary line and was heaving in quality. There was a basal systolic and diastolic murmur. The diastolic murmur was high-pitched, 
starting with the second sound and filling the whole of the diastole. It was best heard in the left parasternal area in the third and fourth intercostal spaces. The basal systolic murmur was harsh and pansystolic. Electrocardiogram showed abnormal left ventricular' preponderance. Fluoroscopy showed enlargement of the left ventricle.

Operation (I.I r.55). The chest was entered through a postero-lateral incision and the sixth rib resected. The lung was totally adherent. The left ventricle was troublesome owing to its size. The aorta was mobilized and four intercostal vessels divided. Following this the aorta was clamped and divided. Four sutures were placed in the edges of the aorta at both ends. The lower end of the valve was in position in 20 minutes. A flap of pleura was turned over the valve and sutured to the root of the lung. The left ventricle, being large, pushed the valve over to the left and caused troublesome angulation and fear was entertained on this account. Immediate post-operative condition was satisfactory. Following a reasonable night the patient was found to have a partially collapsed left lung and complained of backache.

3.I I.55. The haemoglobin was 72 per cent. and one pint of packed cells was given.

4.I 1.55. The haemoglobin remained at 72 per cent. and a further pint of packed cells was given. The lung collapse increased and the patient was bronchoscoped, following which the lung reexpanded.

5.I I.55. The haemoglobin was 70 per cent. and one pint of packed cells was given.

6.I I.55. A further pint of packed cells was given.

7.II.55. The haemoglobin was 76 per cent. One pint of packed cells given.

8.ri.55. The haemoglobin was Ioo per cent. One pint of packed cells given.

9.II.55. Haemoglobin was 95 per cent.

IO.I I.55. Haemoglobin was 86 per cent.

The patient seemed to improve a lot after she had ceased to haemolyze so much blood. On I4.I I. 55 she had a mild attack of precordial pain which lasted about ro minutes and which was the first of its kind since the operation. On I9.II.55 she complained of abdominal pain, which began in the epigastrium and lasted about four hours. Nothing transpired, however, but the possibility of an embolus was noted. On 26.11.55 she began with an epigastric pain, which settled in the right renal angle. She felt sick and the pain continued. Urinary examination was negative. The pain persisted the following day and it was thought that she might possibly have a recto-caecal appendix. Laparotomy was therefore performed. No abnormality was found, however, and the appendix was normal. Nothing, subsequently transpired and she was discharged on 10.12.55, feeling well and better for her operation.

On 29.12.55, at the request of her panel doctor, $\frac{3}{\Phi}$ she was readmitted, as during the past few days $\varrho$ she had had attacks of abdominal colic and had $\stackrel{\hookrightarrow}{\hookrightarrow}$ vomited. These symptoms were repeated but $\stackrel{\vec{F}}{\stackrel{*}{?}}$ without anything serious occurring. Her doctor $\overrightarrow{0}$ diagnosed probable embolus formation and possibly a recurrence of her endocarditis.

On readmission she was found to have no $\frac{\mathbb{D}}{\overparen{O}}$ femoral pulse on the right side, though the leg was quite warm. On 4.I.56 the patient, who had been $\infty$ having repeated small attacks of abdominal pain $\vec{\circ}$ since readmission, suddenly had a very severe $\vec{\overrightarrow{ }}$ abdominal pain and developed abdominal distension. A diagnosis of superior mesenteric throm- $\frac{D}{0}$ bosis was made. She died some hours later.

Post-mortem Examination (5.1.56). The chest was opened. Lung was found to be adherent. The ${ }_{\omega}^{N}$ valve was perfectly embedded and showed no signs of having come loose. The valve was re- $\vec{f}$ moved, together with the aorta, and on examination $\omega_{\infty}$ it was found that there was a small rough patch 웅 in the upper portion of the aorta, close to the clamped edge, where there was some adherent $\Phi$ thrombus. It is probable that it was from here $\frac{\mathbb{O}}{0}$ that the emboli came from time to time. A throm- $\frac{\mathbb{D}}{3}$ bus blocked the right external iliac artery. The heart had diminished in size by nearly half. The patient survived for just over two months ana $\overrightarrow{0}$ again might have done well.

\section{Case 4}

F.I., a man.aged 21 years, was admitted to the Royal Infirmary, Sheffield. He had rheumatic fever at the age of seven years and complained $\stackrel{\circ}{\varnothing}$ of pain in the lower part of the chest at intervals of $\stackrel{\varrho}{\overrightarrow{7}}$ about eight weeks ever since he could remember. Each attack lasted about six days. It was severe for three days and then left a bruised feeling for the remaining time. He had to go to bed during these attacks. He was always short of breath and could do hardly any work.

Examination. The pulse was 76 , regular and ' water hammer' quality. The blood pressure in 8 the upper limbs was $130 / 0$ and in the lower limbs r6o/0. There was visible carotid pulsation. The o apex beat was in the left sixth intercostal space in the mid-axillary line and was heaving in quality. 을. There was a basal systolic and diastolic murmur. The diastolic murmur was soft and high-pitched. $\%$ It was best heard in the left parasternal area in the $N$ third and fourth intercostal spaces. Electro- N cardiogram showed abnormal left ventricular preponderance. The haemoglobin was ro3 per cent.

Operation (23.11.56). The left thorax was $\frac{0}{\mathbb{D}}$ entered through the bed of the resected sixth rib. $\stackrel{0}{\rightarrow}$ The heart, being large, was in some measure in 0 
the way. Difficulty was at once experienced in clearing the pleura from the aorta, as it was densely adherent. The aorta was firmly adherent to all its surroundings. Each intercostal vessel was difficult to identify owing to adhesions and thickened adventitious tissue, which may have been caused by the original rheumatic condition. On dividing the aorta, both ends retracted to a much greater degree than in the other cases and the lumen also shrank, making it very difficult to place the valve of choice, and a smaller one had to be used. By this time the lower end had retracted so much that it was very difficult to get the valve fitted and before the upper end could be fitted the patient suddenly died. Probably the lack of resilience in the aorta may have put greater strain on the heart when the aorta was clamped.

\section{Summary}

Four cases of aortic incompetence following rheumatic fever are described, who were subjected to Hufnagel's operation, of the substitution by a plastic aortic valve. The results and difficulties of the operation are discussed. Although there is nothing spectacular to offer, some of the difficulties and dangers are described.

The changes of the position of the aorta in Case 2 is one which Hufnagel does not describe. Possibly the valve was inserted a little too high.

In Case No. 3 there was very marked postoperative anaemia, only controlled by many transfusions.'

Case No. 4 presented difficulties which we have not seen described, which led to general delay during operation and which may have been a large contribution in causing death.

\section{Hypotensive Technique}

We are indebted to my anaesthetist, Dr. James Johnston, for a few notes on the anaesthetic technique as regards the use of 'Arfonad ' as a pressurereducing agent during the operations. 'Arfonad' is a hypotensive drug used for controlled hypotension in surgery. Its specific action is as a ganglion blocking agent and a vasodilator of the peripheral vessels. Being rapid in its action, it is easy to control, which permits minute to minute checking of the blood pressure.

Case I. A ceiling pressure was obtained of $90 \mathrm{~mm}$. Hg. prior to clamping the aorta, which rose to 140 when the clamp was applied, but fell again quite quickly to $100 \mathrm{~mm}$. During the time which elapsed during the fixation of the valve the pressure remained fairly constant. The total amount of 'Arfonad' used was $750 \mathrm{mg}$. in 120 minutes.

Case 2. A similar amount of 'Arfonad' and rate of flow was used at first. On clamping the aorta the pressure rose to $200 \mathrm{~mm}$. $\mathrm{Hg}$. in spite of the rate of drug flow being increased to over Io mg. per minute. When the valve was functioning, however, the blood pressure fell to the previous ceiling of $100 \mathrm{~mm}$. Hg. and it was thought that the delayed recgvery to normal respiration was due to a relative overdose of curare.

Case 3. It was thought advisable here to withhold 'Arfonad' until the aorta was clamped and signs of increasing hypertension were present. The blood pressure rose steeply to $240 \mathrm{~mm}$. $\mathrm{Hg}$. and the peak had not been reached, so 'Arfonad' was started at a flow rate of $30 \mathrm{mg}$. per minute. The highest reading obtained was $290 \mathrm{~mm}$. $\mathrm{Hg}$., but when the valve was in action the blood pressure fell to $100 \mathrm{~mm}$. $\mathrm{Hg}$. The success of this manoeuvre was most encouraging.

Case 4. In this case a repetitive technique was used. The rate of administration of 'Arfonad ' was $40 \mathrm{mg}$. per minute, but as the case was most difficult and the patient died further readings could not be taken.

In conclusion, we would like to thank Dr. C. S. Darke, who provided two of the cases; Dr. R. Gaunt, for Case No. 3; Dr. J. Johnston, my anaesthetist, for his invaluable help.

\section{BIBLIOGRAPHY}

HUFNAGEL, C. A. (1948), Proc. Surg. Form. Clin. Congress American College of Surgeons, W. B. Saunders \& Co., Philadelphia.

HUFNAGEL, C. A., and GILLESPIE, J. F. (1952), Bull. Georgetown Univ. Med. Centre, 4, 124.

HUFNAGEL, C. A., and HARVEY, W. P. (1953), Bull. Georgetown Univ. Med. Centre, 6, 3

HUFNAGEL, C. A. (1955), Henry Ford Hospital, International Symposium, Saunders \& Co., Philadelphia.

\title{
HOW TO GET THERE
}

An Address Book for the Medical profession, showing how to reach the various Colleges, Societies, Institutes and Hospitals in or near London New (Fourth) Edition: 1954

\author{
FELLOWSHIP OF POSTGRADUATE MEDICINE
}

Price 2s. 6d. (2s. 10d., post free)

Published by the

60 Portland Place, London, W.I 